[Agr. Biol. Chem., Vol. 33, No. 2, p. 242 249, 1969]

\title{
Lactones in the Flavor of Heated Pork Fat*
}

\author{
By Kenji Watanabe and Yasushi Sato \\ Laboratory of Chemistry $\mathbb{E}$ Technology of Animal Products, Department \\ of Agricultural Chemistry, Faculty of Agriculture, \\ Nagoya University, Nagoya, Japan \\ Received August 5, 1968
}

\begin{abstract}
Pork fat was heated at $160 \sim 170^{\circ} \mathrm{C}$ for $3 \mathrm{hr}$ under bubbling with air, and the volatile compounds were collected in the cold trap. After the acidic compounds were removed from the volatile compounds by extraction with $3 \%$ aqueous sodium carbonate solution, lactones were obtained from the nonacidic compounds by saponification. Gas chromatographic analyses of lactones were carried out on the PEG-20M and Apiezon L packed columns, and then each lactone was fractionated by repeated gas chromatography. Each isolated lactone was identified by infrared spectrometry, and also three major lactones were identified by mass spectrometry. Consequently, $\gamma-\mathrm{C}_{5}-\mathrm{C}_{12}$ and $\delta-\mathrm{C}_{9}, \delta-\mathrm{C}_{10}, \delta-\mathrm{C}_{12}$ and $\delta-\mathrm{C}_{14}$ lactones were found in the flavor of heated pork fat. Gamma-lactones, especially $\gamma-\mathrm{C}_{7}$, $\gamma-\mathrm{C}_{8}$ and $\gamma-\mathrm{C}_{9}$, were predominant in the flavor, and unsaturated lactones were not detected. Mechanisms for the formation of the lactones were discussed.
\end{abstract}

Considerable studies $^{1 \sim 4}$ have been carried out on the flavor of heated pork fat, but they have been limited to carbonyl compounds.

It was reported in the previous papers ${ }^{5 \sim 7}$ that beef, pork, mutton, horse, and chicken fats contained 4- and 5-hydroxy fatty acids in their glycerides, and $\gamma$-and $\delta$-lactones detected in these fats were formed from the corresponding hydroxy fatty acids released from glycerides by heating. And also it was suggested that lactones were derived from the oxidation products of unsaturated fatty acids. ${ }^{7 \sim 9)}$

* Studies on the Changes of Meat Fats by Various Processings Part IV.

1) A. M. Gaddis and R. Ellis, Science, 126, 745 (1953).

2) A. M. Gaddis, R. Ellis and G. T. Currie, Food Res., 24, 283 (1959).

3) A. M. Gaddis and R. Ellis, ibid., 24, 392 (1959).

4) L. A. Wishner and M. Keeney, J. Am. Oil Chem. Soc., 42, 776 (1965).

5) T. Nakanishi and K. Watanabe, Nippon Nogeikagaku Kaishi, 40, 222 (1966).

6) K. Watanabe and Y. Sato, Agr. Biol. Chem., 32, 191 (1968).

7) K. Watanabe and Y. Sato, ibid., to be published

8) T. Kawada, B. D. Mookherjee and S. S. Chang, J. Am. Oil Chem. Soc., 43, 237 (1966).
In this paper, it was the aim to make clear the lactones in the flavor of heated pork fat and discuss mechanism of the lactone formaation.

\section{EXPERIMENTAL}

Pork fat. Sample of about $30 \mathrm{~kg}$ of pork fat was obtained from commercial source.

Heat treatment and collection of heated pork fat flavor. The apparatus used for the heat treatment and collection of volatile compounds of the heated pork fat is shown in Fig. 1. One $\mathrm{kg}$ of pork fat, in each collection, was heated at $160 \sim 170^{\circ} \mathrm{C}$ for $3 \mathrm{hr}$ under bubbling with air (two bubbles/sec.), and the volatile compounds and steam were drawn with the current of air blowing through the apparatus into trap A (cooled with ice water), trap B and $\mathrm{C}$ (cooled with ice containing $\mathrm{NaCl}$ ) and trap $\mathrm{D}, \mathrm{E}$ and $\mathrm{F}$ (cooled with dry ice in acetone). The collected volatile compounds in each trap were washed out with ethyl ether. In order to remove the fat jumped into trap A during heating, the concentrated ethyl ether extract obtained from the

9) J. A. Fioriti, V. Krampl and R. J. Sims, J. Am. Oil Chem. Soc., 44, 534 (1967). 


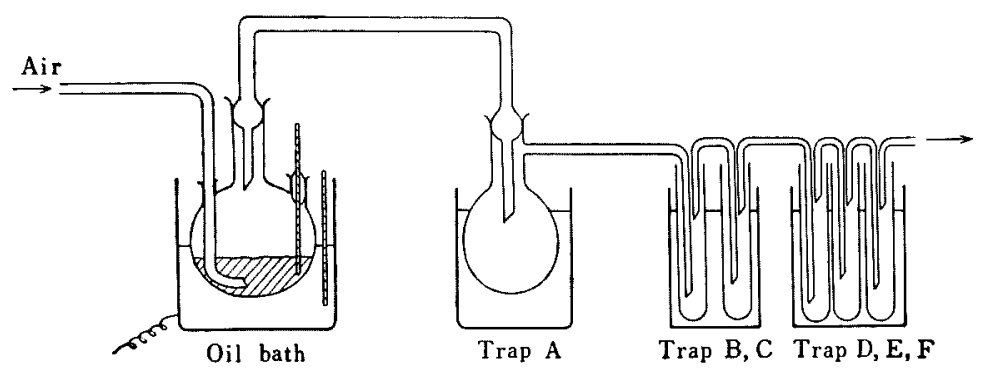

FIG. 1. The Apparatus Used for Heating_and_Collection of Volatile Compounds.

Table I. Conditions for Gas Chromatography

\begin{tabular}{cllll} 
Condition & GC Model & \multicolumn{1}{c}{ Column } & \multicolumn{1}{c}{ Temp. ${ }^{\circ} \mathrm{C}$} & Carrier Gas \\
I & K-53 & Apiezon L & $40 \stackrel{2{ }^{\circ} \mathrm{C} / \mathrm{min}}{\longrightarrow} 200$ & $\mathrm{~N}_{2}, 0.3 \mathrm{~kg} / \mathrm{cm}^{2}$ \\
II & K-53 & PEG-20M & $150 \stackrel{2{ }^{\circ} \mathrm{C} / \mathrm{min}}{\longrightarrow} 230$ & $\mathrm{~N}_{2}, 0.3 \mathrm{~kg} / \mathrm{cm}^{2}$ \\
III & K-53 & Apiezon L & $100 \stackrel{2{ }^{\circ} \mathrm{C} / \mathrm{min}}{\longrightarrow} 230$ & $\mathrm{~N}_{2}, 0.3 \mathrm{~kg} / \mathrm{cm}^{2}$ \\
IV & KGL-2A & PEG-20M & 170 & $\mathrm{He}, 60 \mathrm{ml} / \mathrm{min}$ \\
V & KGL-2A & Apiezon L & $148^{*}, 165^{* *}, 190^{* * *}$ & $\mathrm{He}, 60 \mathrm{ml} / \mathrm{min}$
\end{tabular}

Note: Star marks of $*, * *$, and $* * *$ show the column temp. for fractionation of $\gamma-\mathrm{C}_{5}$ to $\gamma-\mathrm{C}_{8}, \gamma-\mathrm{C}_{9}$ to $\gamma-\mathrm{C}_{11}$ and $\delta-\mathrm{C}_{12}$ to $\delta-\mathrm{C}_{14}$, respectively.

trap A was steam-distillated at $40^{\circ} \mathrm{C}$ under the reduced pressure. The distillate was extracted with ethyl ether, and the extract was combined with other extracts from trap B, C, D, E and F, together.

Fractionation of volatile compounds. The volatile compounds in the combined ethyl ether extract were fractionated into acidic and nonacidic compounds by extraction with $3 \%$ aqueous sodium carbonate solution. The acidic compounds in water layer will be reported in the following papers. A part of nonacidic compounds in ethyl ether was analysed by gas chromatography, and another part of them was stirred three times with $1 / 2$ volumes of $0.1 \mathrm{~N} \mathrm{KOH}$ solution for $1 \mathrm{hr}$ in order to saponify lactones at room temperature. The soap solution obtained from the saponified lactones was slowly acidified with $6 \mathrm{~N} \mathrm{HCl}$ to $\mathrm{pH} 2$ and then extracted four times with equal amounts of ethyl ether. The ethyl ether solution was dried over anhydrous $\mathrm{Na}_{2} \mathrm{SO}_{4}$ to facilitate lactonization of the 4- and 5-hydroxy fatty acids. Most of the ethyl ether was removed by distillation prior to gas chromatographic analysis of the lactone fraction.

Analysis of the lactone fraction by gas chromatography. The gas chromatography (GC) on the lactone fraction was carried out by using a Hitachi K-53 Model Gas Chromatograph with a flame ionization detector. To confirm the idenity of lactones both polar and nonpolar packed columns were used. The columuns were: $2 \mathrm{~m}, 4 \mathrm{~mm}, 20 \% \mathrm{PEG}-20 \mathrm{M}$ on $30 / 60$ mesh Chromosorb WAW, and $2 \mathrm{~m}, 3 \mathrm{~mm}, 20 \%$ Apiezon $\mathrm{L}$ on $30 / 60$ mesh Chromosorb WNAW. The conditions of $\mathrm{GG}$ are shown in Table I. Authentic lactones $\left(\gamma-\mathrm{C}_{5}, \mathrm{C}_{6}, \mathrm{C}_{8}, \mathrm{C}_{9}, \mathrm{C}_{11}\right)$ obtained from commercial source, tentatively identified lactones $\left(\gamma-\mathrm{C}_{10}, \mathrm{C}_{12}, \delta-\mathrm{C}_{14}\right)$ in the previous paper $\left.{ }^{6}\right)$ and synthetic lactones $\left(\delta-\mathrm{C}_{10}\right.$, $\mathrm{C}_{12}$ ) were used for comparison.

Fractionation of lactones by $G C$. The fractionation of each lactone was carried out by using a Hitachi KGL-2A Model with a thermal conductivity detector. The columns used for analysis of lactones were utilized for the fractionation. The conditions are shown in Table I.

The eluent represented by each of the gas chromatographic peaks separated on PEG-20M packed column (Condition IV in Table I), was collected in capillary tube cooled with dry ice in methanol. This procedure was due to the method of Miyazaki et al. ${ }^{101}$ which is

10) A. Miyazaki et al., unpublished work. 
the improved technique reported by Kawada et al. ${ }^{8}$ Amounts of $40 \mu \mathrm{l}$ of the concentrated lactone fraction was injected each time. The GC was repeated six times. Lactones in six capillary tubes corresponding to a peak in gas chromatogram were washed out with ethyl ether, and the washed lactones were combined together. Each combined lactone was again separated on Apiezon $\mathrm{L}$ packed column (Condition $\mathrm{V}$ in Table I). This procedure was repeated two or three times and the eluents were collected in each capillary tube.

Infrared and mass spectroscopy of isolated lactones. The infrared spectra were obtained from a Nihon Bunko IR-E Infrared Spectrophotometer using $0.1 \mathrm{~mm}$ $\mathrm{NaCl}$ cell. Carbon tetrachloride were injected into each capillary tube using microsyringe and carbon tetrachloride solution in capillary tube was transferred into the cell. The purity of isolated lactones was confirmed with samples recovered from the cell under the condition II of GC (Table I). Fractionation by GC was again carried out under the condition of rechromatograph procedure (Condition $\mathrm{V}$ in Table $\mathrm{I}$ ) in sample which did not show the single peak in gas chromatogram.

Mass spectra of lactones collected in capillary tubes were measured with Hitachi Mass Spectrometer RMU$4 \mathrm{D}$.

\section{RESULT AND DISCUSSION}

1. Gas chromatogram of the nonacidic compounds The nonacidic compounds had a burnt-like odor, and it could not be recognized clearly that the aromatic flavor of lactone was present in their odor. Gas chromatogram of the nonacidic compounds was shown in Fig. 2. It was shown that a great many compounds were present in the nonacidic compounds. The nonacidic compounds, from which lactones were isolated, were named neutral compounds. Gas chromatography of the neutral compounds gave the result that there was little difference between the gas chromatograms of the nonacidic and neutral compounds except a peak which had the same retention time as that of $\gamma-\mathrm{C}_{8}$ lactone. Its difference is shown in Fig. 2. It might be presumed that lactones had the same retention times as that of the neutral compounds, and the differences were not shown clearly in gas chromatograms even though there were lactones in the nonacidic fraction. The neutral compounds will be reported in the following papers.

\section{Gas chromatogram of lactones}

Gas chromatogram of lactones, and the retention times of GC are shown in Fig. 3 and Table II, respectively. Judging from the retention times and relative retention times of both polar and nonpolar packed columns, it was suggested that $\gamma-\mathrm{C}_{5}-\mathrm{C}_{12}, \delta-\mathrm{C}_{10}, \delta-\mathrm{C}_{12}$ and $\delta-\mathrm{C}_{14}$ were present in the flavor of heated pork fat. Peak No. (PN) 8 might be $\delta-\mathrm{C}_{9}$, estimating the result of a linear relationship between logarithm of the relative retention times and

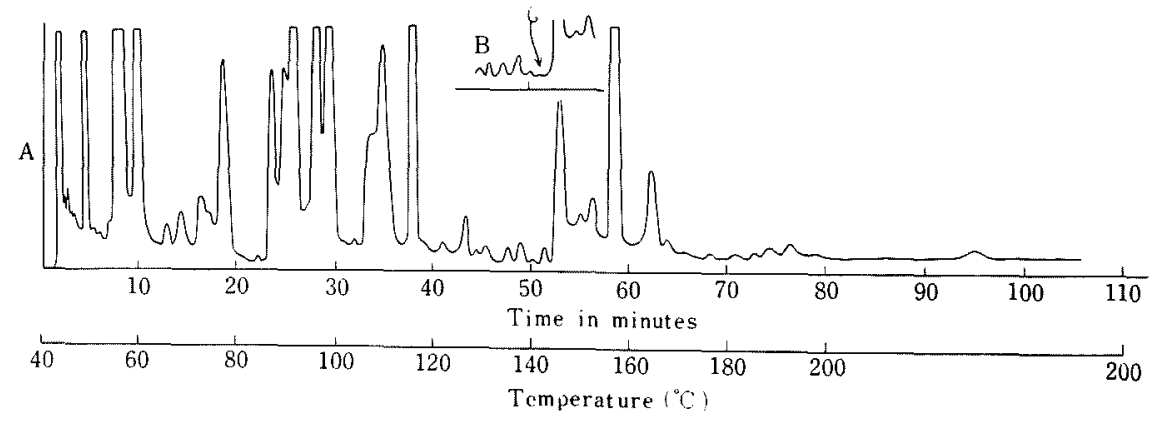

FIG. 2. Gas Chromatograms of Nonacidic and Neutral Compounds under Condition I.

A: Nonacidic Compounds B: Neutral Compounds
$\downarrow$ showes a peak which disappeared by saponification. 


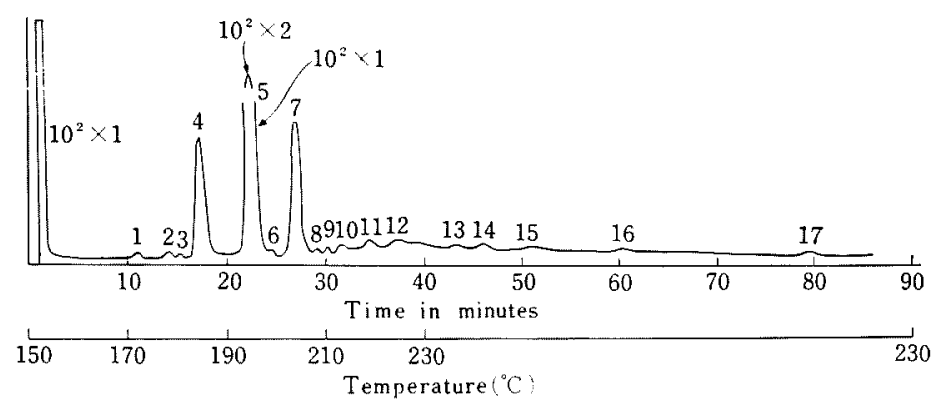

FIG. 3. Gas Chromatogram of Lactones under Condition II.

TABLE II. Retention TIME OF Reference AND SAMple Lactones AND ReLative Retention TIME To $\gamma-\mathrm{C}_{9}$

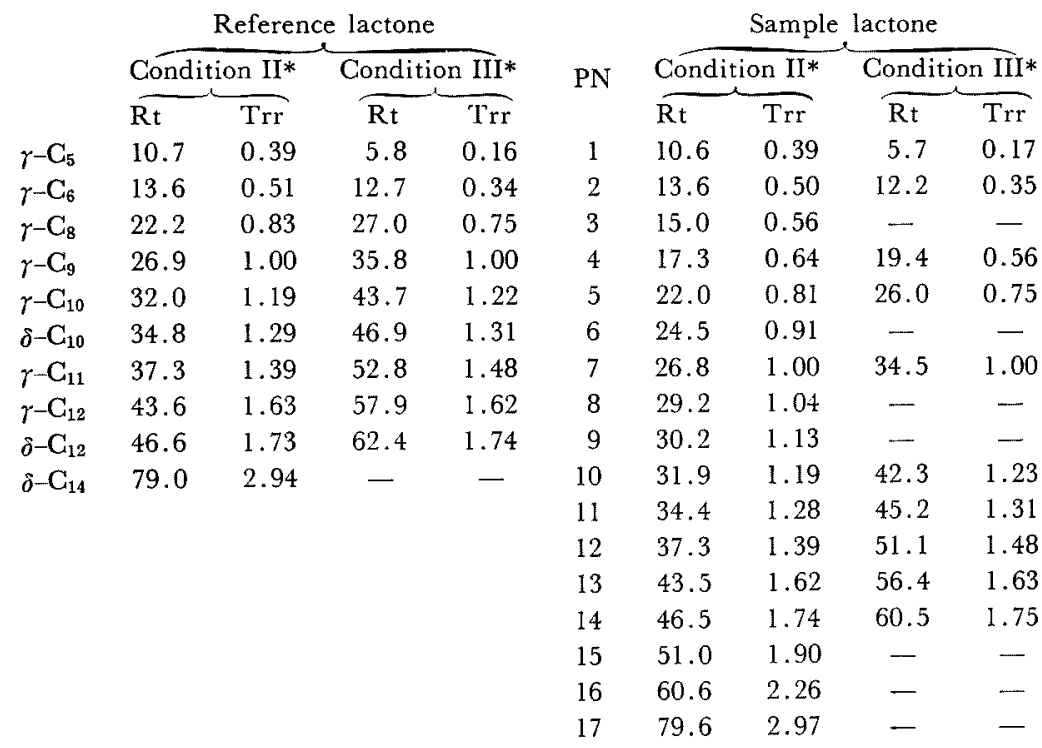

* shown in Table I, PN: Peak No. in Fig. 3, Rt: Retention time, Trr: Relative retention time to $\gamma-\mathrm{C}_{9}$.

carbon numbers in homologous series of $\delta$ - of isolated lactones showed the absorption at lactones in the condition described in the 1775 or $1735 \mathrm{~cm}^{-1}$ previous paper. ${ }^{6}$

\section{Infrared spectra of isolated lactones}

Infrared spectra of isolated lactones are shown in Fig. 4. The carbonyl stretching vibration of $\gamma$ - and $\delta$-lactones were at 1775 and $1735 \mathrm{~cm}^{-1}$, respectively. Infrared spectra

\section{Mass spectra of isolated lactones}

Mass spectra of PN 4, 5 and 7 in Fig. 3 are shown in Fig. 5. Prominent ions of $\mathrm{m} / \mathrm{e}$ $85\left[\mathrm{CH}-\mathrm{CH}_{2}-\mathrm{CH}_{2}-\mathrm{C}=\mathrm{O}\right]^{+}$i. e. loss of the side chain, was observed in all of spectra. Lactones 

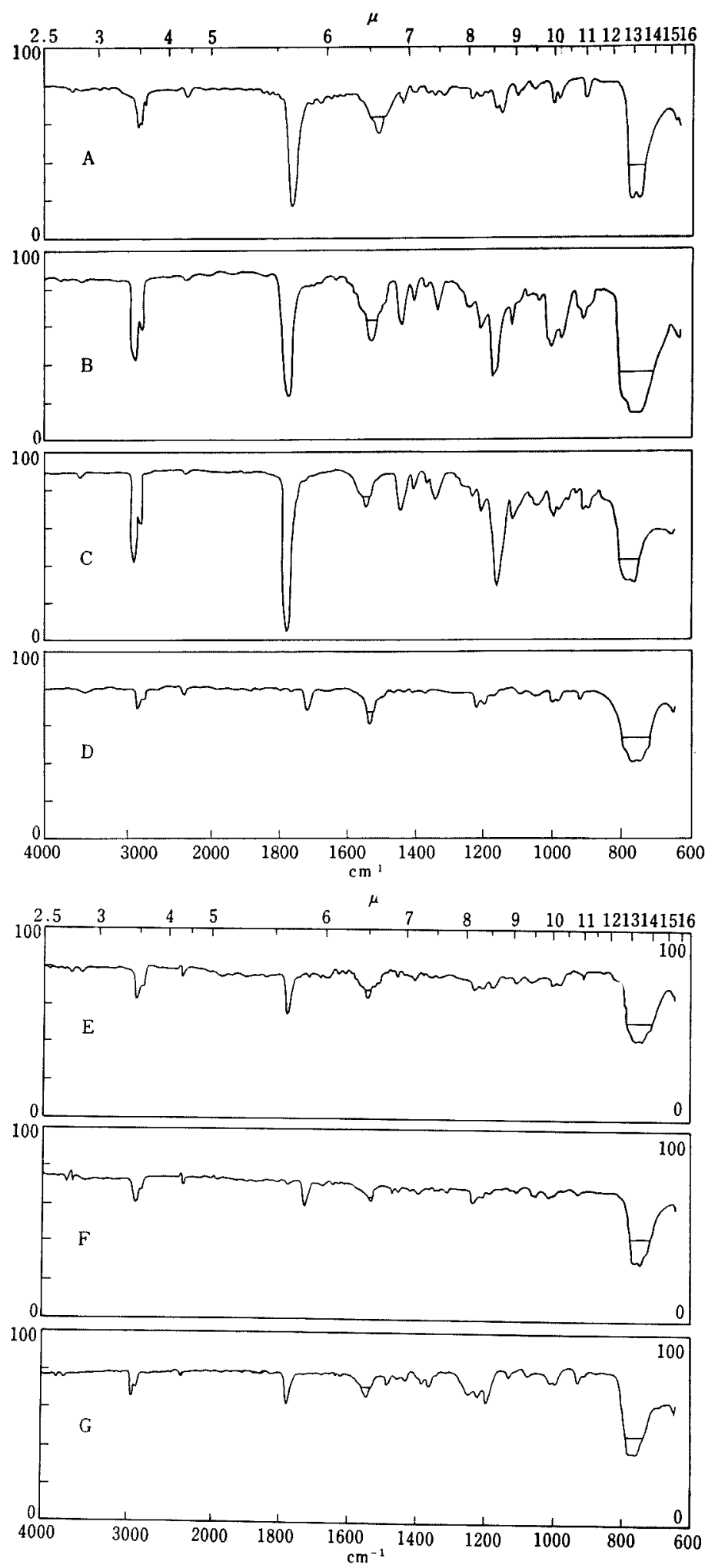

FIG. 4. Infrared Spectra of Isolated Lactones. 


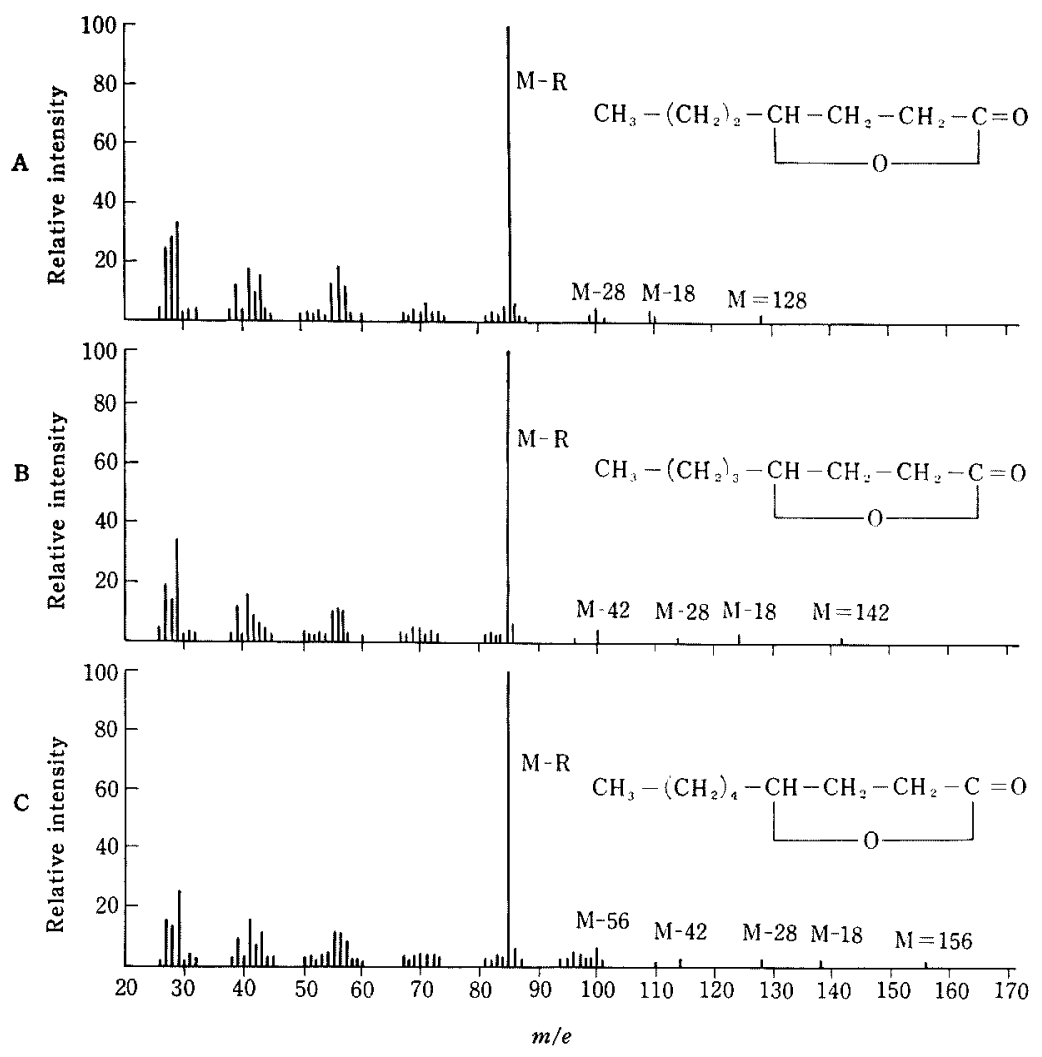

FIG. 5. Mass Spectra of Isolated Lactones.

A: PN-4, B: PN-5, C: PN-7, PN: Peak No. in Fig. 3.

of PN 4, 5 and 7 were shown to be gamma form. These spectra followed the general patterns of $\gamma$-lactones resported by McFadden et al. ${ }^{11)} \mathrm{PN} \mathrm{4,5}$ and 7 were identified as $\gamma-\mathrm{C}_{7}$, $\gamma-\mathrm{C}_{8}$ and $\gamma-\mathrm{C}_{9}$ as shown in Fig. 5.

\section{Summary of identified lactones}

Consequently, it seemed to be reasonable to admit that $\gamma-\mathrm{C}_{5}(\mathrm{PN}-1), \gamma-\mathrm{C}_{6}(\mathrm{PN}-2), \gamma-\mathrm{C}_{12}$ (PN-13), $\delta$ - $\mathrm{C}_{12}(\mathrm{PN}-14)$ and $\delta-\mathrm{C}_{14}(\mathrm{PN}-17) \mathrm{judg}-$ ing from retention times in gas chromatograms, $\delta$ - $\mathrm{C}_{9}(\mathrm{PN}-8), \gamma-\mathrm{C}_{10}(\mathrm{PN}-10), \delta-\mathrm{C}_{10}(\mathrm{PN}-11), \gamma-\mathrm{C}_{11}$ (PN-12) from retention times and infrared spectra, and $\gamma-\mathrm{C}_{7}(\mathrm{PN}-4), \gamma-\mathrm{C}_{8}(\mathrm{PN}-5)$ and $\gamma-\mathrm{C}_{9}$

11) W. H. McFadden, E. A. Day and M. J. Diamound, Anal. Chem., 37, 89 (1965).
(PN-7) from retention times, infrared and mass spectra, were present in the flavor of heated pork fat. Ratio of $\gamma-\mathrm{C}_{7}, \gamma-\mathrm{C}_{8}$ and $\gamma-\mathrm{C}_{9}$, which were the major components, was $21.7: 51.7$ : 26.6. Amounts of the other lactones were only traces. $\mathrm{PN}-3,6,9,15$ and 16 were not identified because of trace amounts, and they were not investigated further. Although 4hydroxy-2-heptenoic and 4-hydroxy-2-nonenoic acids were identified in the heated corn oil by Krishnamurthy et al., ${ }^{121}$ unsaturated lactones could not be detected in this study.

The unfractionated lactone extract seperated from the nonacidic compounds had a butter-

12) R. G. Krishnamurthy and S. S. Chang, $J \cdot A m$. Oil Chem. Soc., 44, 136 (1967). 
like flavor, while their flavor could not be felt in the nonacidic fraction. The essential role of the lactones in imparting a characteristic and desirable flavor to heated pork fat could not be confirmed, because the burnt odor was stronger. It seemed pertinent to do the quantitative analysis of lactones formed during short period of heating.

Important suggestions to be drawn from this study were that $\gamma$-and $\delta$-saturated lactones were present rather in the oxidized pork fat, and $\gamma$ lactones were more predominant than $\delta$-lactones. acids. Fioriti et al. ${ }^{91}$ reported that lactones were not detected in fresh and refined soybean oil, and were found in highly peroxidized samples of cottonseed and soybean oils. Kawada et $a l^{81}$ demonstrated the presence of $\gamma-\mathrm{C}_{6}$ and $\gamma-\mathrm{C}_{9}$ lactones in the flavor of hydrogenated soybean oil, and postulated mechanisms for the formation of $\gamma-\mathrm{C}_{6}$ lactone. Their mechanisms were characteristic in consideration of unsaturated hydroxy fatty acid as intermediate. Mechanism of $\gamma-\mathrm{C}_{6}$ lactone formation is proposed as follows:

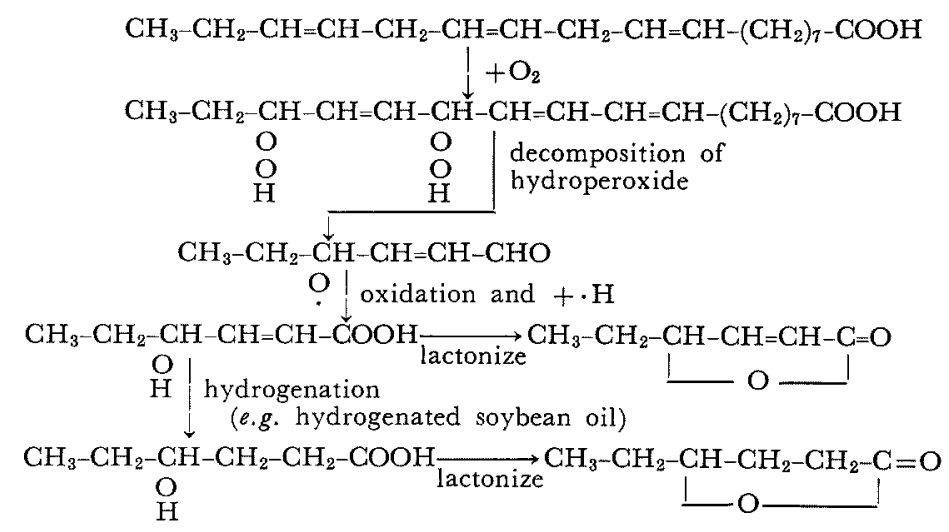

\section{Intermediates of lactone formation}

It was reported in the previous paper ${ }^{71}$ that meat fat contained esterified 4- and 5-hydroxy fatty acids in glycerides as the precursors of $\gamma$ - and $\delta$-lactones. But as has been discussed, it must be recalled that lactones might be derived from the oxidation products of fatty
It may be sure that unsaturated lactones were derived from the decomposition of hydroperoxides of unsaturated fatty acids. But this mechanism could not be adopted in this study, because unsaturated lactones were not found in the heated pork fat. Another mechanism for the formation of saturated lactones is postulated as follows:

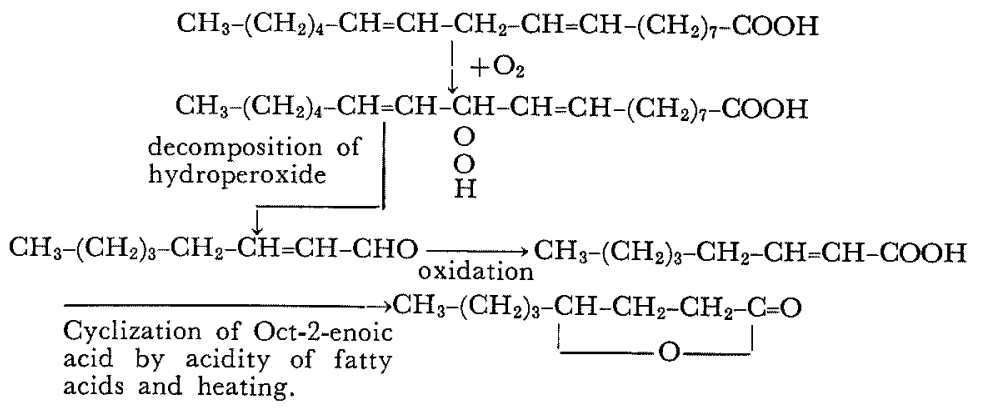


Ansell et al. ${ }^{13)}$ reported that alkenoic acids were lactonized by refluxing with $50 \%$ sulphuric acid and were changed to $\gamma$-saturated lactones and small amounts of $\delta$-lactones. It was assumed that alkenoic acids, formed through the oxidation of unsaturated fatty acids, were perhaps lactonized into the corresponding lactones accelerated by acidity of fatty acids and heating. Mechanism of only $\gamma-\mathrm{C}_{8}$ lactone formation was described above. It might be mentioned that the other lactones were formed through similar way.

13) M. F. Ansell and M. H. Palmer, J. Chem. Soc., 1962, 2649.
It could not be distinguished whether the isolated lactones were derived from 4- and 5hydroxy fatty acids in glycerides, or from the oxidation products of fatty acids, even if these postulated mechanisms are correct. Attention may be drawn to this problem in the further studies.

Acknowledgement. The authors take this opportunity to express their thanks to Professor T. Nakanishi, Tohoku University, for his interest in this work and encouragement, and are much indebted to $\mathrm{Mr}$. A. Miyazaki of Nagoya University for his helpful advice and determination of mass spectra. 